\title{
Competing responses in a differential magnitude of reward discrimination'
}

\section{JOHN R. MacKINNON, ${ }^{2}$ University of Toronto, Toronto, Canada}

The incidence of alley retracing was recorded in a differential reward magnitude discrimination. Five groups of rats received 500 $m g$ reward to one stimulus $\left(S_{1}\right)$ and either $500,250,90,37$, or 0 $m g$ reward to the other $\left(S_{2}\right)$. Following training, extinction trials were run to $S_{1}$ only. The retracing patterns observed were discussed in the context of frustration theory.

Several experiments involving differential reward magnitude discrimination have shown that performance to one stimulus is not independent of the reward magnitude associated with the other stimulus in the discrimination (e.g., Bower, 1961; Davenport, 1962; Ludvigson \& Gay, 1967; MacKinnon, 1967). An interpretation of how the interactive effects of the two incentives determine performance in such a discrimination is provided by an extension of frustrative nonreward theory (Amsel, 1958). The suggestion is that frustrative responses are generated to the small reward stimulus through the generalization of anticipatory goal reactions $\left(r_{G} s\right)$ from the large reward discriminandum. The development of anticipatory small-reward-produced frustration to the small reward stimulus should result in the elicitation of competing responses which act to retard performance to that stimulus. Furthermore, it has been shown (MacKinnon, 1967) that performance to the large reward stimulus is inversely related to the intensity of the small-reward-produced frustration.

The present data. collected in conjunction with standard runway performance measures (MacKinnon, 1967), trace the development of an easily recorded competing behavior (i.e., the alley retrace) in a discrimination based on differential magnitudes of reward, and provide additional support for a theoretical interpretation based on small-reward-produced frustration.

$$
\text { METHOD }
$$

The apparatus, described in detail elsewhere (MacKinnon, 1967), consisted of two parallel alleys, one painted flat black and the other flat white. A common prestart (PSB) and start box (SB) unit, painted flat gray, was separated from the alley proper by a Plexiglas door. Performance measures (start, running, and goal times) were recorded over successive $1-\mathrm{ft}$ segments of the alley. Inside dimensions of each alley were $3-3 / 4 \mathrm{in} . \times 3 \mathrm{in}$. The final 13 in. of the nunway, when enclosed by a metal guillotine door, served as the goal box (GB).

Sixty male albino rats, approximately 120 days old, were assigned randomly to five groups, designated as Groups 500:500, $500: 250,500: 90,500: 37$. and 500:0, and were run. six trials per day, with three of the daily trials to one alley brightness $\left(S_{1}\right)$, and three to the other $\left(S_{2}\right)$. The numerals of the group labels indicate the $S_{1}: S_{2}$ reward magnitudes (in $\mathrm{mg}$ ). (olor conditions were counterbalanced within groups, and orders of presentation of $S_{1}$ and $S_{2}$ were randomized. Following discrimination training $(72$ trials to each stimulus). Ss received 24 extinction trials to $S_{1}$, the stimulus associated with $500 \mathrm{mg}$ reward for all groups during training. Minimum GB detention time was $20-25 \mathrm{sec}$, and the intertrial interval averaged $18 \mathrm{~min}$.

A retrace was recorded when $\mathrm{S}$ completely reversed its forward locomotion to the $G B$, and returned toward the SB. Only the first retrace on any trial was counted, and retraces occurring in the PSB and $G B$ were not included in the results.

RESULTS AND DISCUSSION

The retracing pattern to $S_{2}$ over the course of discrimination is shown in Fig. 1. The carly development of retracing in Ciroups $500: 37$ and 500:0 suggests a stage of training when strong generalized approach tendencies $\left(r_{R}\right.$ 's) and small reward or nonreward-produced anticipatory avoidant tendencies to $S_{2}$ are in competition. A comparison of these retrace data with the runway speed data (Mackinnon, 1967) reveals that the greatest incidence of retracing in Groups 500:37 and 500:0 (Blocks 3 and 4)

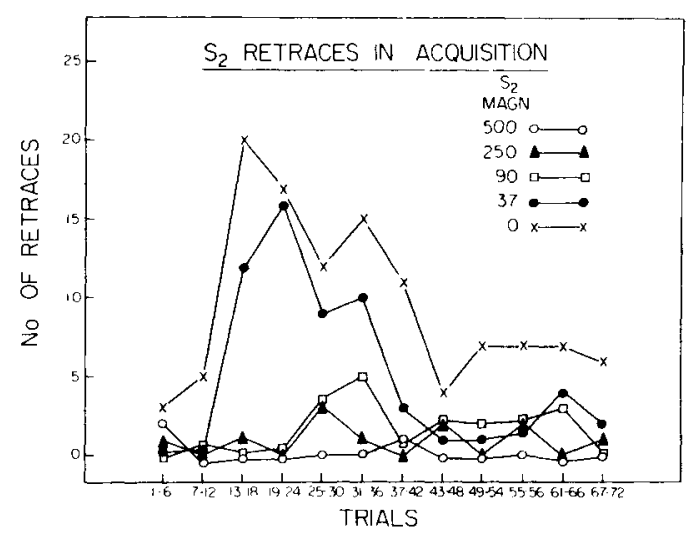

Fig. 1. Total number of retraces to $S_{2}$ during discrimination training.

coincides with the development of discrimination in the start measure, as evidenced by a sharp decrease in starting speeds to $S_{2}$. The data shown in Fig. I include only the first retrace on any individual trial, and although retraces in all segments are included here, most first retraces occurred in the initial segment of the runway. The general finding that the formation of a discrimination is concurrent with the development of competing responses to $S_{2}$ is compatible with a frustration interpretation.

There was almost a complete absense of retracing to $S_{2}$ in Groups 500:500,500:250, and 500:90, although there is a slight indication of competing behavior in the latter group. Overall, Fig. 1 indicates that the number of retraces to $S_{2}$ is inversely related to the magnitude of reward associated with that stimulus. As for performance to $S_{1}$ (not shown), no retracing was seen in any group af ter the first few acquisition trials.

It is evident from Fig. 1 that following the early development of retracing in Groups 500:0 and 500:37, there is a gradual decline in the incidence of retracing over the course of discrimination training. The decrease in retracing over the latter trials suggests that stimulation associated with anticipatory small-rewardproduced avoidance tendencies (Group 500:37) or with nonreward-produced frustration (Group 500:0), becomes conditioned to approach with extended training.

Although this interpretation is consistent with the running speed performance of Group 500:37 (MacKinnon, 1967), an examination of the speed data for the simple discrimination condition (Group 500:0) reveals that the effect of frustrative factors varies with alley segment. As the incidence of retracing decreases over Trial Blocks 4-8, inc. (Fig. 1), start speed to $S_{2}$ shows at slight increase, whereas running and goal speeds decline. The increase in start speed to $S_{2}$ may be accounted for by assuming that strong generalized $r_{R}$ is present when $S_{2}$ is initially encountered. The interaction of this generalized $r_{R}$ and $r_{F}$ may provide the condition for the facilitory effect of frustration (i.e., $s_{1} \rightarrow$ Approach). On the other hand, running and goal performance reflects, essentially, "post-discriminative behavior" and is controlled mainly by strong avoidance tendencies (i.e., $\mathrm{s}_{\mathrm{l}} \rightarrow$ Avoid). In other words, $s_{F} \rightarrow$ Avoid is the dominant tendency once the initial response to the discriminative cue has been made.

Retracing to $S_{1}$ over the 24 extinction trials is shown in Fig. 2. The five groups differed significantly beyond the .001 level $(\mathrm{F}=23.79, \mathrm{df}=4 / 55)$ and subsequent individual comparisons of the group means by Duncan's multiple-range test (Edwards, 1960) revealed the following: Groups 500:500 and 500:250 differed significantly $(\mathrm{p}<.05)$ in mean number of retraces, and both these groups differed $(p<.05)$ from the other three groups. Differences 


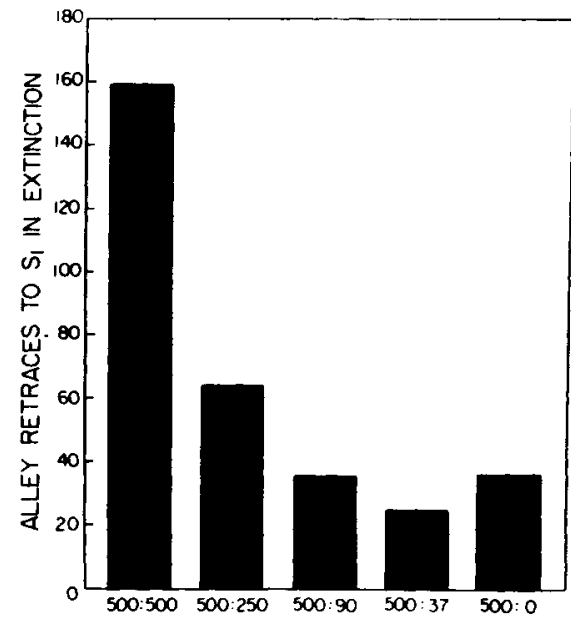

Fig. 2. Total number of retraces to $S_{1}$ for the five groups in extinction

among Groups 500:90, 500:37, and 500:0, however, were not reliable.

These results indicate a rough inverse relationship between the incidence of retracing to $S_{1}$ in extinction and the number of retraces made to $S_{2}$ during training. Presumably, fewer competing responses should occur to $S_{1}$ in extinction for the groups which had learned to approach $S_{2}$ in the presence of strong anticipatory small-reward-produced frustration cues during training (Groups $500: 90,500: 37$, and 500:0). Similarly, Ss trained to approach $S_{2}$ in the presence of relatively weak cues (Group 500:250) or in the absence of such cues (Group 500:500), should exhibit the highest incidence of competing behavior in extinction.

Although the above data do not warrant a conclusive statement on the role of competing responses in differential magnitude of reward discriminations, there is an obvious consistency between these findings and theoretical assumptions based on frustration theory. However, further research employing more specific quantification of various competing behaviors is necessary in order to provide a comprehensive competing response interpretation of performance in differential reward magnitude discrimination.

\section{REFERENCES}

AMSEL, A. The role of frustrative nonreward in noncontinuous reward situations. Psychological Bulletin, 1958, 55, 102-119.

BOWER, G. H. A contrast effect in differential conditioning. Journal of Experimental Psychology, 1961, 62, 196-199.

DAVENPORT, J. W. The interaction of magnitude and delay of reinforcement in spatial discrimination. Joumal of Comparative \& Physiological Psychology, 1962, 55, 267-273.

EDWARDS, A. L. Experimental design in psychological research. New York: Rinehart, 1960.

LUDVIGSON, H. W., \& GAY, S. E. An investigation of conditions determining contrast effects in differential reward conditioning. Journal of Experimental Psychology, 1967, 75, 37-42.

MacKINNON, J. R. Interactive effects of the two rewards in a differential magnitude of reward discrimination. Joumal of Experimental Psychology, $1967,75,329-338$.

\section{NOTES}

1. This paper is based on auxiliary data collected in a thesis experiment submitted in partial fulfillment of the requirements for the Ph.D. degree at the University of Toronto. The research was supported by NSF Grant GB-3772 to A. Amsel.

2. Now at Connecticut College, New London. 